\title{
The impact of voluntary fortification practices on adequacy of micronutrient intake in older adults in Ireland
}

The voluntary addition of micronutrients to foods represents one strategy to alleviate suboptimal micronutrient intake at a population level ${ }^{(1)}$. The discretionary nature of such additions by food manufacturers highlights the importance of monitoring the efficacy and safety of such practices on an on-going basis. The objective of this study was to quantify the impact of voluntary food fortification on reducing the prevalence of inadequate micronutrient intake in a representative sample of older adults in Ireland ( $\geq 65$ years), using data from the National Adult Nutrition Survey (NANS) (2008-2010). The NANS used a 4-day semi-weighed food and beverage record to estimate habitual food and nutrient intake. Food intake data were collected at brand level, allowing for the identification of fortified foods (FFs) by the presence of micronutrients in the ingredient list. The prevalence of inadequate intake of selected micronutrients in consumers of FFs $\left(n\right.$ 176) was assessed using estimated average requirements ${ }^{(2,3)}$ and compared with corresponding values which would result if foods had not been fortified. McNemar's test was used to assess significant changes in the prevalence of inadequate intake. Under-reporters (URs), defined by using minimum energy intake cut-off points ${ }^{5}$ calculated as multiples of BMR (Tanita, Japan) were excluded from the analysis.

FFs ( $n 66,5.2 \%$ of foods recorded) were consumed by over three-quarters of older adults (77-78\%) and contributed $8.9 \%$ and $10.8 \%$ to mean daily energy intake in men and women respectively. The main FFs consumed by this population group were ready-to-eat breakfast cereals, bread \& rolls, fat spreads and reduced-fat milks, which contributed $2.9 \%, 2.2 \%, 2.0 \%$ and $1.3 \%$ to mean daily energy intake respectively.

\begin{tabular}{|c|c|c|c|c|c|c|}
\hline \multirow[b]{3}{*}{ Nutrient } & \multicolumn{6}{|l|}{$\%<$ EAR } \\
\hline & \multicolumn{3}{|l|}{$\operatorname{Men}(n=61)$} & \multicolumn{3}{|l|}{$\operatorname{Women}(n=71)$} \\
\hline & Pre-fortification & After fortification & $P$ value & Pre-fortification & After fortification & $P$ value \\
\hline Vitamin A & 8.2 & 6.6 & 1.000 & 5.6 & 4.2 & 1.000 \\
\hline Vitamin $\mathrm{D}<10 \mu \mathrm{g}$ & 86.9 & 83.6 & 0.500 & 76.1 & 74.6 & 1.000 \\
\hline Vitamin $\mathrm{D}<5 \mu \mathrm{g}$ & 59.0 & 50.8 & 0.063 & 59.2 & 49.3 & 0.016 \\
\hline Riboflavin & 6.6 & 6.6 & 1.000 & 7.0 & 2.8 & 0.250 \\
\hline Vitamin B12 & 1.6 & 0.0 & 1.000 & 1.4 & 1.4 & 1.000 \\
\hline Folate & 8.2 & 4.9 & 0.500 & 15.5 & 7.0 & 0.031 \\
\hline Vitamin $\mathrm{C}$ & 11.5 & 9.8 & 1.000 & 5.6 & 4.2 & 1.000 \\
\hline Calcium & 8.2 & 6.6 & 1.000 & 9.9 & 8.5 & 1.000 \\
\hline Iron & 6.6 & 4.9 & 1.000 & 21.1 & 8.5 & 0.004 \\
\hline Zinc & 18.0 & 18.0 & 1.000 & 11.3 & 11.3 & 1.000 \\
\hline Magnesium & 31.1 & 31.1 & 1.000 & 28.2 & 28.2 & 1.000 \\
\hline
\end{tabular}

Our study found that the addition of nutrients to foods had a significant impact in reducing the prevalence of inadequate intake of folate, iron and vitamin $\mathrm{D}<5 \mu \mathrm{g} / \mathrm{d}$ in women aged 65 years and over. No significant reduction was observed in men. Fortification had no significant impact on reducing the prevalence of inadequate magnesium, zinc and vitamin $\mathrm{C}$. In conclusion, current voluntary fortification practices are effective in improving intakes and adequacy for some, but not all micronutrients in this population group.

1. Hennessy Á, Walton J, Flynn A (2013) Proc Nutr Soc 73, 433-440.

2. Department of Health (1991) London: H.M.S.O.

3. Food and Nutrition Board (2011) Washington D.C.: Institute of Medicine. 